\title{
Peri-operative management of hysterostomy in a parturient with complete heart block, placenta accreta and intrauterine death
}

Vineya Rai ${ }^{1 *}$, Ina I Shariffuddin ${ }^{1}$, Yoo K Chan ${ }^{1}$, Rajesh K Muniandy ${ }^{2}$, Kang K Wong ${ }^{1}$ and Sukcharanjit Singh ${ }^{1}$

\begin{abstract}
Background: Complete heart block in pregnancy has serious implications particularly during the period of delivery. This is more so if the delivery is an operative one as the presence of heart block may produce haemodynamic instability in the intra operative period. We report a unique case of a pregnant mother with complete heart block undergoing hysterostomy, complicated by placenta accreta and intrauterine death.

Case presentation: A 37 year old Malaysian Chinese parturient was admitted at 25 weeks gestation following a scan which suggested intrauterine death and placenta accreta. She was diagnosed to have congenital complete heart block after her first delivery eight years previously but a pacemaker was never inserted. These medical conditions make her extremely likely to experience massive bleeding and haemodynamic instability. Among the measures taken to optimise her pre-operatively were the insertion of a temporary intravenous pacemaker and embolization of the uterine arteries to minimize peri-operative blood loss. She successfully underwent surgery under general anesthesia, which was relatively uneventful and was discharged well on the fourth post-operative day.

Conclusion: Congenital heart block in pregnancies in the presence of potential massive bleeding is best managed by a team, with meticulous pre-operative optimization. Suggested strategies would include insertion of a temporary pacemaker and embolization of the uterine arteries to reduce the risk of the patient getting into life threatening situations.
\end{abstract}

Keywords: Complete heart block, Pregnancy, Hysterostomy, Hysterectomy

\section{Background}

Complete heart block $(\mathrm{CHB})$ in pregnancy is not a common encounter [1]. However it has serious implications in pregnancy particularly during the period of delivery. This is more so if the delivery is an operative one as the presence of heart block may not allow the mother to respond well to haemodynamic instability. There are reports of cases of congenital complete heart block in the literature where mothers have been paced temporarily but there are equally others where no pacemakers were used. Those who are managed without pacemakers risk having complications, including death.

We report the successful management of a parturient with a unique set of problems besides just congenital

\footnotetext{
* Correspondence: vineya74@yahoo.com

'Department of Anaesthesiology, Faculty of Medicine, University of Malaya, 50603 Kuala Lumpur, Malaysia

Full list of author information is available at the end of the article
}

CHB. She had placenta accreta and intrauterine death needing hysterostomy which put her at extreme risk of massive bleeding and haemodynamic instability. The strategies for safe management included the prophylactic insertion of a temporary intravenous pacemaker and the pre-emptive embolization of the uterine arteries which has been shown in other studies to minimize blood loss perioperatively [2].

\section{Case presentation}

The patient, a 37 year old Malaysian Chinese parturient (Gravida 4 Para $2+1$ ) was admitted at 25 weeks gestation following a routine scan which suggested intrauterine death. A repeat scan done when she had per vaginal bleeding confirmed the death and showed a grade 3-4 placenta praevia with suggestions of a placenta accreta.

Her two previous deliveries were via caesarean section for breech delivery 8 and 6 years prior to the current 
event in another hospital. She was confirmed to have a congenital complete heart block after her first delivery and was followed up in the National Heart Insitute where she was treated conservatively. Throughout the period of current and previous pregnancies, she has never been symptomatic of CHB; chest pain, palpitations or syncopal attacks. Her ECG showed a complete heart block with narrow QRS complex, indicating a high nodal impulse with a rate of $50 / \mathrm{min}$ (Figure 1). Her blood pressure was $140 / 80 \mathrm{mmHg}$. Bedside echocardiogram was relatively normal except for mild mitral regurgitation. Her serum thyroid stimulating hormone and antinuclear antibody levels were normal. Coagulation profile showed a slightly elevated prothrombin time of $1.24 \mathrm{~s}$ and an international normalized ratio of 1.3. Her fibrinogen levels were normal.

The obstetrician opted for hysterostomy to deliver the baby with an alternative plan of performing a caesarean hysterectomy in the event of uncontrolled bleeding. Prior to the surgery, bilateral uterine artery embolization was performed by a radiologist. A temporary intravenous pacemaker was also inserted by a cardiologist.

General anesthesia was induced with fentanyl $100 \mu \mathrm{g}$, etomidate $18 \mathrm{mg}$ and suxamethonium $100 \mathrm{mg}$. Anaesthesia was maintained with $2 \%$ sevoflurane in oxygen/air $50 \%$. Pain relief was with morphine boluses and continued muscle relaxation with rocuronium. Tranexamic $1 \mathrm{~g}$ was also infused intra-operatively.

Patient's heart rate was monitored and averaged between 50-60 beats/minute which did not require pacemaker activation. Intra-arterial blood pressure monitoring did not show any instability. The patient's haemodynamics remained stable intra-operatively (Figure 2).

The total blood loss was $1.2 \mathrm{~L}$ and patient was transfused 3 units of packed cells intra-operatively. The preoperative haemoglobin was $11.3 \mathrm{~g} / \mathrm{dL}$ and the immediate post-operative value was $7.9 \mathrm{~g} / \mathrm{dL}$. A total abdominal hysterectomy was done to control the bleeding.

Post-operatively, the patient was extubated as she remained stable hemodynamically. She was monitored in the intensive care unit and the pacemaker was removed 48 hours later as she remained stable hemodynamically. Patient was discharged home on the 4th post-operative day.

\section{Discussion}

Complete heart block, also known as third degree atrioventricular (AV) or simply third degree heart block is a disorder of the cardiac conduction system with complete

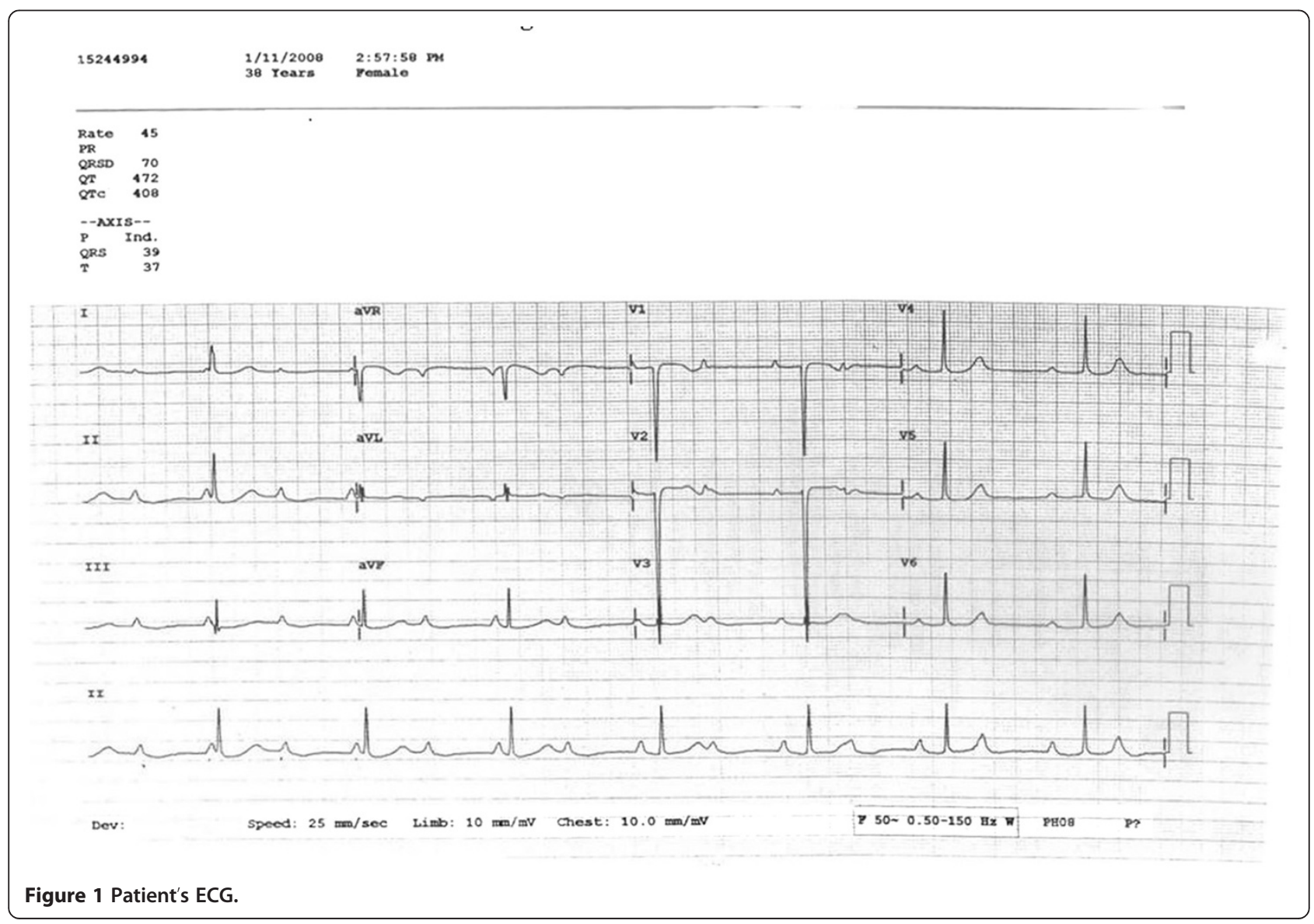




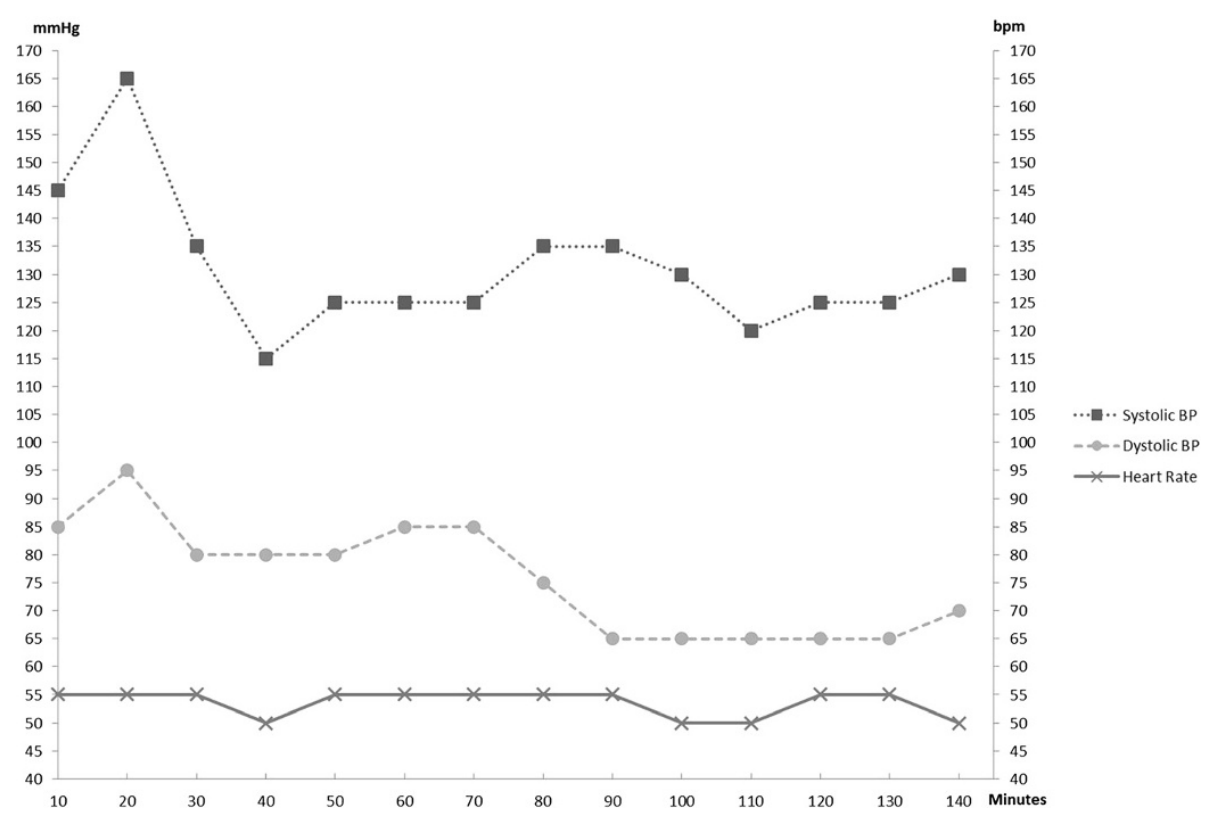

Figure 2 Patient's peri-operative blood pressure and heart rate.

absence of AV conduction. Aetiologically, CHB can be divided into two groups: congenital complete heart block and acquired complete heart block (ACHB) [3]. Congenital $\mathrm{CHB}$ in pregnancy is associated with connective tissue disease but this was not present in our patient. Most cases reported in the literature suggest that uncomplicated brady-arrhythmia during pregnancy in the absence of significant underlying heart disease, results in a favourable outcome for both mother and baby. In addition, uncomplicated brady-arrhythmias including asymptomatic CHB has not been reported to cause any maternal death [4]. However, our patient also had additional risk factors mainly massive bleeding secondary to placenta accreta and potential disseminated intravascular coagulation. Thus, our patient is unique in that when faced with massive bleeding, she potentially would not be able to mount an adequate heart rate response due to the CHB. In light of that, a temporary pacemaker was inserted to cope with this likely possibility.

In the 1950s, Epstein and Altman suggested that without pacemaker insertion, pregnancy in women with complete heart block was associated with high maternal and fetal mortality [5]. However, subsequent case series reported experiences without the insertion of pacemaker in uncomplicated pregnancies and deliveries [6]. These deliveries however were not at risk of obstetric haemorrhage. While our patient did not at any juncture use the temporary pacemaker, we felt that the insertion was fully justified to cover for the eventuality of a life-threatening situation.

The team took measures to reduce the risk of haemorrhage by ensuring that she had no coagulation abnormality despite the intra-uterine death. Bilateral uterine artery embolization was performed in this patient before the fetus was delivered as it was already confirmed dead. This procedure does not compromise long term uterine integrity [7]. Traditional methods of controlling obstetric haemorrhage are by bilateral uterine artery or hypogastric artery ligation. These traditional methods produce low success rates in bleeding reduction due to the presence of extensive collateral circulation in the pelvis and has been estimated to be as low as $42 \%$ [8]. This is in comparison to embolization which has a success rate of more than 90\% [9]. In addition, if a caesarean hysterectomy is needed, embolization can slow the rate of blood loss hence improving the surgical field. Caesarean hysterectomy in the presence of severe haemorrhage is an extremely challenging procedure which carries a high risk of iatrogenic damage to other pelvic structures especially ureters and bladder [10]. Slowing the rate of blood loss improves the surgical field, making the procedure technically easier thus reducing the risk of surgical complications [11]. In the presence of a significant blood loss in our patient, the team felt it was safer to proceed with hysterectomy to reduce the risk of post partum bleeding.

In patients at risk of major haemorrhage, choosing the best form of anaesthesia can be challenging. The advantage of regional anaesthesia is that it omits the use of volatile agents, which may contribute to uterine atony. Regional anaesthesia has also been shown to reduce transfusion requirements [12-14]. We chose general anaesthesia over regional anaesthesia as our patient had a definite risk of major obstetric haemorrhage complicated 
with CHB. With general anaesthesia, we had a better haemodynamic control and could focus on keeping up with the blood loss correction. Furthermore, the risk of conversion from regional to general anaesthesia at the time of torrential haemorrhage may add to further cardiovascular instability.

Etomidate was chosen over thiopentone as our induction agent as the former has been shown to be superior in maintaining cardiovascular stability. With the pacemaker in place we felt confident about using fentanyl, etomidate and suxamethonium, the combination of which can potentially cause bradycardia [15]. Our patient did not suffer this complication during the induction process.

\section{Conclusion}

In summary, congenital $\mathrm{CHB}$ in pregnancies in the presence of potential massive bleeding is best managed as a team, with meticulous pre-operative optimization. Suggested strategies would include insertion of a temporary pacemaker and embolization of the uterine arteries in situations where excessive bleeding is likely to contribute to a life threatening situation.

\section{Consent}

Written informed consent was obtained from the patient for publication of this case report. A copy of the written consent is available for review by the Editor of this journal.

\section{Abbreviations \\ ECG: Electrocardiogram; INR: International normalized ratio; CHB: Complete heart block; ACHB: Acquired complete heart block; AV: Atrioventricular.}

\section{Competing interests}

The authors declare that they have no competing interests.

\section{Authors' contributions}

VR: Preparation of the manuscript and involvement in the case. IIS: Anesthesiologist involved in the case. YKC: Conceived of the study, and participated in its design and coordination and helped to draft the manuscript. RKM: Preparation of the manuscript. KKW: Preparation of the manuscript. SS: Preparation of the manuscript. All authors read and approved the final manuscript.

\section{Acknowledgements}

This study was supported by the University Malaya Research Grant (UMRG) RG365/11HTM

\section{Author details}

'Department of Anaesthesiology, Faculty of Medicine, University of Malaya, 50603 Kuala Lumpur, Malaysia. ${ }^{2}$ Department of Medicine Based, School of Medicine, Universiti Malaysia Sabah, Kota Kinabalu, Sabah, Malaysia.

Received: 4 March 2014 Accepted: 25 June 2014

Published: 28 June 2014

\section{References}

1. Sullivan JM, Ram Nathan KB: Management of medical problems in pregnancy-severe cardiac disease. N Engl J Med 1985, 313:304-309.
2. Yu P, Ou H, Tsang L, Kung F, Hsu T, Cheng Y: Prophylactic intraoperative uterine artery embolization to control hemorrhage in abnormal placentation during late gestation. Fertil Steril 2009, 91:1951-1955.

3. Adekanye O, Srinivas K, Collis RE: Bradyarrhythmias in pregnancy: A case report and review of management. Int J Obstet Anesth 2007, 16:165-170.

4. Department of Health: Report on Confidential Enquiries into Maternal Deaths 1982-1984. In Report on Health and Social Subjects no 34. London: HMSO; 1989.

5. Epstein JR, Altman HE: Heart block in pregnancy; report of two cases. Med Ann Dist Columbia 1951, 20:660-663.

6. Hidaka N, Chiba Y, Kurita T, Satoh S, Nakano H: Is intrapartum temporary pacing required for women with complete atrioventricular block? An analysis of seven cases. Int J Obstet Gynaecol 2006, 113:605-607.

7. Fiori O, Deux J, Kambale J, Uzan S, Bougdhene F, Berkane N: Impact of pelvic arterial embolization for intractable postpartum hemorrhage on fertility. Am J Obstet Gynecol 2009, 200(4):384.

8. Clark SL, Phelan JP, Yeh S, Bruce SR, Paul RH: Hypogastric artery ligation for obstetric hemorrhage. Obstet Gynecol 1985, 66:353-356.

9. Hansch E, Chitkara U, McAlpine J, El-Sayed Y, Dake MD, Razavi MK: Pelvic arterial embolization for control of obstetric hemorrhage: A five year experience. Am J Obstet Gynecol 1999, 180(6):1454-1460.

10. Abbas F, Talati J, Wasti S, Akram S, Ghaffar S, Qureshi R: Placenta percreta with bladder invasion as a cause of life threatening hemorrhage. $J$ Urol 2000, 164:1270-1274.

11. Mok M, Heidemann B, Dundas K, Gillespie I, Clark V: Interventional radiology in women with suspected placenta accreta undergoing caesarean section. Int J Obstet Anesth 2008, 17:255-261.

12. Hong JY, Jee YS, Yoon HJ, Kim SM: Comparison of general and epidural anesthesia in elective cesarean section for placenta previatotalis: maternal hemodynamics, blood loss and neonatal outcome. Int I Obstet Anesth 2003, 12:12-16.

13. Parekh N, Husaini SW, Russell IF: Caesarean section for placenta praevia: a retrospective study of anaesthetic management. $\mathrm{Br} J$ Anaesth 2000, 84:725-730

14. Chestnut DH, Dewan DM, Redick LF, Caton D, Spielman FJ: Anesthetic management for obstetric hysterectomy: a multi-institutional study. Anesthesiology 1989, 70:607-610.

15. Inoue K, Reichelt W: Asystole and bradycardia in adult patients after a single dose of suxamethonium. Acta Anaesthesiol Scand 1986, 30:571-573.

doi:10.1186/1471-2253-14-49

Cite this article as: Rai et al:: Peri-operative management of hysterostomy in a parturient with complete heart block, placenta accreta and intrauterine death. BMC Anesthesiology 2014 14:49.

\section{Submit your next manuscript to BioMed Central and take full advantage of:}

- Convenient online submission

- Thorough peer review

- No space constraints or color figure charges

- Immediate publication on acceptance

- Inclusion in PubMed, CAS, Scopus and Google Scholar

- Research which is freely available for redistribution 